Territorios 34 / Bogotá, 2016, pp. 35-58

ISSN: 0123-8418

ISSNe: 2215-7484

La fase actual del capitalismo y la urbanización en América Latina (I)

\title{
Processos e problemas na urbanização da América Latina: teoria e história
}

Processes and Problems in Latin American Development:

Theory and History

Procesos y problemas en el desarrollo de América Latina:

teoría e historia

Paulo Cesar Xavier Pereira*

Recebido: 30 de julho de 2015

Aprovado: 27 de agosto de 2015

Doi: dx.doi.org/10.12804/territ34.2016.02

Para citar este artigo

Pereira, P. C. X. (2016). Processos e problemas na urbanização da América Latina: teoria e história, Territorios, 34, 35-58. Doi: dx.doi.org/10.12804/territ34.2016.02

* Faculdade de Arquitetura e Urbanismo, Universidade de São Paulo. Correo electrónico:pcxperei@usp.br 
Palavras-chave

Colonial, globalização, imobiliário, neoliberal, reestruturação.

Palabras clave

Colonial, globalización, inmobiliario, neoliberal, reestructuración.

Keywords

Colonial, globalization, real estate, neoliberal, restructuring.

territarias 34

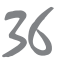

\section{RESUMO}

Este artigo analisa as condições históricas da produção da cidade latino-americana e tem como referência o desenvolvimento urbano de São Paulo. A discussão objetiva contribuir à compreensão teórica das peculiaridades dos processos de urbanização e de acumulação industrial na construção para enfatizar que as relações não capitalistas estão na origem da produção capitalista do espaço urbano e que a persistência histórica de ditas relações em conjunto com as relações capitalistas serviu tanto à superexploração quanto à sobrevivência dos trabalhadores. Na atualidade este espaço da cidade e resulta fundamental para a sobrevida do capitalismo garantindo alta rentabilidade com a renda da terra e as taxas de lucro.

\section{RESUMEN}

Este artículo analiza las condiciones históricas de la producción de las ciudades en América Latina y tiene como referencia el desarrollo urbano de São Paulo. El objetivo de la discusión es contribuir a la comprensión teórica de las peculiaridades de los procesos de urbanización y de acumulación industrial en la construcción para enfatizar que las relaciones no capitalistas están en el origen de la producción capitalista del espacio urbano y que la persistencia histórica de dichas relaciones, en combinación con las relaciones capitalistas, sirvió tanto a la sobreexplotación como a la supervivencia de los trabajadores. En la actualidad, este espacio de la ciudad resulta fundamental para la supervivencia del capitalismo, lo que garantiza altas ganancias con la renta del suelo y las tasas de interés.

\section{ABSTRACT}

This article analyzes the historical conditions of production of Latin American cities and it has as a reference to the urban development of São Paulo. The main objective of this discussion is to contribute to the theoretical understanding of the peculiarities of the processes of urbanization and industrial accumulation in the construction to emphasize that non-capitalist relations are at the root of capitalist production of urban space, and that historical persistence of such relations combined with capitalist relations served both to overexploitation and to the survival of workers. Currently, this area of the city is essential for the survival of capitalism, guaranteeing high profits through ground rent and interest rates. 


\section{Introdução}

A referência à cidade de São Paulo dentro do contexto dos estudos sobre a urbanização na América Latina se justifica tanto pelos problemas atuais quanto por sua história. Atualmente, é uma das maiores aglomerações industriais e trata-se do primeiro assentamento colonial português a se localizar distante da faixa litorânea. Desde, o primeiro momento de fundação deste núcleo urbano se expressava a intenção do capital em expansão de levar adiante a conquista de território e o domínio de "gentes da terra" utilizando os métodos da chamada acumulação primitiva de capital.

A característica dessa forma de acumulação é a utilização de processos de expropriação, desapropriação ou espoliação de pessoas vulneráveis que perdem condições de vida e se veem impedidas de acessar os bens comuns, quando não são, elas mesmas, destituídas da condição de pessoa e de sua liberdade. Historicamente, a dinâmica da acumulação primitiva se manifesta de maneira distinta e apresenta particularidades conforme região, formação urbana, consolidação industrial ou maneira como concorreu à constituição dos estados nacionais. Apesar das diferentes dinâmicas, a crueldade dos métodos foi um ponto comum revelando a voracidade dos processos e como, apesar das reações geradas, não se conseguiu impedir a colonialidade como maneira de manter as relações entre os povos colonizados com os centros de poder. Nesse sentido, pretende-se que a discussão teórica e histórica dos processos de acumu- lação primitiva, bem como a identificação de problemas relativos à construção, urbanização e crescimento das cidades latinoamericanas, permitam reconhecer os fundamentos pelo qual persistem a dominação metropolitana e o poder do colonizador que fragilizam o direito à cidade.

Considera-se que, embora a urbanização e a construção das cidades apresentem situações particulares importantes, há processos que aproximam suas histórias. Nessa mesma conjunção, os problemas apresentam semelhanças e convergem para o traço comum, que é a desigualdade nas cidades latino-americanas. Essa constatação é relevante porque a urbanização planejada poderia minorar a segregação ao imprimir dinâmica menos perversa à construção dessas cidades e à solução do problema habitacional, mesmo que capitalista. Vale reter essas considerações iniciais para discussão porque "nuestros patrones culturales parecen proveer más oportunidades de integración social que las que solemos atribuirles" (Sabatini \& Trebilcock, 2013, p. 38) e certamente cabe às políticas urbanas, mesmo que atendendo de maneira mercantil e capitalista as diferenciadas demandas sociais, tornar as cidades mais justas.

Chama à atenção que as políticas públicas e os programas habitacionais e de qualificação urbana pouco impactam o direito à cidade: as cidades latino-americanas continuam sendo injustas e muito desiguais. Historicamente, embora a urbanização tenha apresentado avanços e alguns dos resultados possam ser considerados exemplos de integração social, é preciso lembrar que territarias 34 
recente relatório sobre a condição dessas cidades confirma a persistências de problemas tradicionais e que as "desigualdades socioeconómicas en la región también se hacen evidentes en términos de calidad de viviendas y del acceso a servicios públicos” (ONU Habitat, 2014, p. 166). Por isso, cabe ressaltar que esta é mais uma publicação de importante organismo mundial a indicar que a América Latina se constitui na região mais desigual do mundo, ainda que se possa fazer a ressalva de que, atualmente, o ritmo do crescimento da desigualdade esteja diminuindo.

América Latina e Caribe sempre tiveram cidades segmentadas social e territorialmente. Esse artigo tem em vista aprofundar o conhecimento histórico sobre a persistência dessa situação e pretende refinar a crítica sobre os processos que a produzem. Assim, desigualdade urbana é o objeto privilegiado dessa discussão, que é realizada sob a perspectiva da produção do espaço e propõe o estudo da "cidade, como um lugar particular da manifestação concreta dos processos sociais e urbanos, que materializa em sua característica e seu devenir o resultado histórico no qual se insere" (Pereira, 1985, p. 143). Pretende-se que a unidade da reconstituição do processo urbano com a crítica teórica da explicação dos problemas relativos à construção social da cidade e do acesso à habitação permitirá compreender porque persiste nas cidades latino-americanas tamanha injustiça urbana.

territarios 34 38 vo como as relações não capitalistas dos momentos iniciais da colonização se manifestaram em um processo de acumulação originária e tenderam, no transcorrer desses séculos, a persistir em função das necessidades da emergência da acumulação do capital, que parece não ter fim. Entende-se que por essa perspectiva histórica e crítica será possível melhor compreender como, nas formas de apropriação e de produção do espaço ibero-americano, persistiu o uso de relações não capitalistas fomentando a urbanização precária. Essas relações não capitalistas consorciadas a processos primitivos de acumulação se afirmam ainda mais a partir da segunda metade do século XIX, quando se consolidou o desenvolvimento da produção do espaço, ora afirmando ora negando o caráter capitalista das formas de expansão urbana e da industrialização da construção (Pereira, 1988 e 2004).

A discussão desse desenvolvimento ambíguo em que a cidade latino-americana, como uma totalidade em função das necessidades do capital, é produzida por relações não capitalistas se mostra decisivo para uma perspectiva crítica da urbanização e compreensão dos fundamentos da persistente desigualdade dessa cidade. Essa compreensão é relevante porque no transcorrer do século XX as condições de construção da cidade industrial moderna aprofundaram o caráter desigual desse desenvolvimento combinando exploração do trabalhador com espoliação do morador. E é notável a relevância dessa combinação, nessa passagem para o século XXI, quando a nova condição da cidade intensifica os processos da metropolização e dissolve o urbano em 
espaço metropolitano. Essa transformação é mundial e se combina com a dissolução local das condições urbanas devido a instrumentalização do espaço pela economia financeira globalizada, que metamorfoseia a cidade no espaço metropolitano (Pereira, 2014).

Em face desse desenvolvimento se verifica que, historicamente, a reprodução do capital na construção gerou ganhos de exploração do trabalho que se somaram com os ganhos de processos espoliativos, sejam eles urbano, imobiliário ou financeiro. Essa potenciação do trabalho de construir por processos espoliativos foi tradicionalmente exacerbada na América Latina, onde se usou e abusou da massa urbana de trabalhadores mal pagos tendo que pagar preço alto para morar na cidade. A exploração e espoliação dessa massa urbana permite compreender como a construção da cidade latino-americana se caracterizou pela combinação de uma diversidade de formas de produção do espaço, que ampliam a oferta dos produtos da construção e respondem às diversas possibilidades de equacionar a demanda por habitação. Cabe ainda notar que cada forma de produção, nessa diversidade, busca maximizar o uso da terra e a capitalização das rendas. E fazem com que a partir dos anos 1970 se destaquem os processos espoliativos, que acabam por marcar a passagem para o século XXI com a retomada da acumulação primitiva (Pereira, 2006, 2011). Por isso, torna-se necessário precisar o significado desses processos espoliativos financeiro, urbano e imobiliário na produção do espaço da cidade contemporânea.
Trata-se de pôr em relevo a emergência das novas condições urbanas e da política de construção da cidade. Por isto, interessa discutir o que esse quadro emergente pode significar para a cidade latino-americana já que os métodos da acumulação primitiva se mostram persistentes. Assim, busca-se esclarecer como a instrumentalização da terra tornou-se significativa e porque o espaço se tornou uma condição de sobrevida do capital. Enfim, considera-se que a análise dos processos de espoliação permitirá compreender a precariedade urbana e a exacerbação da desigualdade, como o maior desafio à justiça e ao direito à cidade.

\section{Assentamentos coloniais e a acumulação originaria do capital}

São Paulo, fundada em janeiro de 1554 , seguiu o caminho histórico universal que caracteriza a inserção das cidades latinoamericanas no mundo capitalista. Esta característica geral é a inserção comercial subordinada à economia do mundo, que marcaria inclusive a sua evolução, sendo necessário compreender a sua marca essencial: o "sentido da colonização", conforme Prado (1979). Enfim esta inserção subordinada trata-se de algo problemático, mas persistente tendo se constituído em empecilho para a organização do Estado-Nação e para a formação industrial caracterizando o atrelamento do desenvolvimento latinoamericano ao capitalismo dos países centrais (Pradilla, 2013).

Assim, desde o primeiro século da colonização, São Paulo, tal como outros territarias 34 
assentamentos ibero-americanos, se colocou a serviço da reprodução do capital e pode desde sempre ser considerada como um núcleo da urbanização que se expandia a nível mundial associada ao capital mercantil. A identificação desse processo de urbanização colonial mercantilista não quer dizer, porém, que não ocorram "geografias da urbanização" manifestando irregularidades e descontinuidades muito diversas dessa história. Trata-se do secular processo urbano do capitalismo histórico manifestando variações mundiais na configuração do tempo e do espaço, que na unidade da produção global do capital no espaço latino-americano acontece de modo subordinado e com desvantagem de posicionamento, fazendo persistir relações não capitalistas. Ressalte-se que é a antípoda do que ocorre nas aglomerações do Atlântico norte onde as:

$[\ldots]$ vantagens de posicionamento $[\ldots]$ nas sucessivas mudanças espaciais que alteraram os centros dos processos sistêmicos de acumulação: 'Amsterdam copiou Veneza, tal como Londres viria posteriormente a copiar Amsterdam e como Nova York, um dia copiaria Londres.' [em] que cada mudança esteve associada a uma verdadeira 'revolução organizacional' nas estratégias e estruturas do agente preponderante da expansão capitalista (Arrighi, 1996, pp. 14-15).

Frente a essas estratégias e estruturas organizacionais, ganha relevância resgatar o significado das aglomerações latino-americanas para a história do capitalismo desde a primeira mudança que altera os centros da acumulação e não, como é frequente, discutir essas desvantagens e subordinação apenas após a Revolução Industrial. Assim, aqui será mantida "a afirmação de Braudel de que a mudança refletiu 'a vitória de uma nova região sobre uma antiga', combinada com 'uma vasta mudança de escala'", tal como foi por Arrighi (1996, p. 15), mas com o agravante de que a América Latina, região periférica, continua sendo perdedora.

Quanto à particularidade da evolução do assentamento paulista, cabe relevar que em seus 462 anos a cidade de São Paulo foi construída utilizando a técnica de construção da taipa de pilão e preservando relações não capitalistas de produção do espaço por cerca de dois terços de sua história, todos os seus primeiros trezentos anos. Mas, ainda no último século e meio, percorrendo, portanto todo século $\mathrm{xx}$, o crescimento das franjas da urbanização desta cidade, que se transforma em metrópole, está marcado por forte presença da relação não capitalista na sua expansão territorial. Ainda é visível na paisagem irregular, o contraste entre as construções altas e ruas modernas, de um lado, com o casario precário e o traçado tortuoso e estreito, de outro. E, apesar de que a análise das estatísticas confirme que as relações assalariadas capitalistas tenham se desenvolvido e se tornado socialmente dominantes, parece não haver dúvida de que persiste a combinação delas com relações consideradas “atrasadas". Pior, em anos recentes, deste século, tem sido divulgado na imprensa 
diária a existência de situações semelhantes a do trabalho escravo encontradas em canteiros de obras de grandes empresas construtoras realizando edifícios modernos em áreas centrais da cidade e na ampliação do aeroporto metropolitano.

Assim, se pretende discutir como a ambiguidade da combinação e convivência dessas relações sociais - simbiose de relações capitalista e não capitalista - determina a configuração da cidade. Em absoluto, não se quer afirmar aqui a existência de qualquer relação direta e reflexa da conformação social sobre a configuração espacial. Ao contrário, pretende-se que o conhecimento da conformação ambígua do urbano além de situar suas marcas no processo histórico e imediato da produção do espaço apresente a crítica das variações espaço-tempo que precisam ser consideradas para se compreender os processos e os problemas de construção da cidade. Por isso, além da perspectiva histórica, a hipótese dessa simbiose tem relevância teórica precisando ser aprofundada tendo em vista melhor caracterizar a desigualdade urbana e a diversidade das formas de produção do espaço. Busca-se, portanto, recuperar a tradição da análise histórica e estrutural da sociedade associada à perspectiva da produção social do espaço, porque entendo que ambas estão obscurecidas e caberia propor trabalhos coletivos e de alcance internacional que pudessem resgata-las com enfoque capaz de pensar a América Latina.

Nos primeiros séculos da colonização, São Paulo teve os edifícios de taipa construídos com trabalho compulsório dos indígenas locais e aprisionados em missões jesuíticas no território espanhol (Amaral, 1981) e depois houve a utilização de escravos africanos que fez persistir e tornou homogênea, no Planalto Paulista, essa técnica de construção. Assim, internamente, “a introdução do trabalho africano não constitui modificação fundamental, pois apenas veio substituir outro escravo eficiente e de recrutamento mais incerto" (Furtado, 1964, p. 62).

Em São Paulo, [inicialmente] a utilização do escravo africano não foi significativa, e o uso contínuo dos chamados 'negros da terra' foi sempre o predominante, oscilando entre formas diversas de trabalho compulsório, até o pagamento de 'mesquinhos salários'. Isto certamente era devido ao fato da produção colonial paulista ser secundariamente subordinada à metrópole, a qual contava, como fundamental, com a produção açucareira do Nordeste. No sistema implantado a produção de exportação colonial significava produzir para acelerar a acumulação primitiva de capital que dominava todo o processo de colonização moderno (Pereira, 1988, pp. 17-18).

Inserida nesse projeto de exploração colonial, a fundação de cidades no espaço ibero-americano respondia às necessidades da acumulação originária porque significava a possibilidade de acesso a riquezas e a conquista de um território no qual seriam realizadas atividades econômicas em grande escala sob a forma: a) de expropriação por empresa estrangeira de um bem já territarias 34 41 
existente, sobretudo mineral; b) exploração por estrangeiros de grandes plantações de produtos a serem exportados e c) produção agrícola e pecuária para exportação realizada por grupos locais (Castells, 1973). Mas, nunca se limitou apenas a essa dimensão da reprodução social, pois havia também a produção imediata de construir a cidade com uma arquitetura e com espaços institucionais novos e, ainda, a preocupação de criar o convívio das pessoas pelas quais se procurava transplantar o evangelho e outros elementos para a formação da vida colonial. Nesse sentido, os primeiros colonizadores repetiram o que vinha sendo praticado desde a Reconquista, assegurando o sucesso do empreendimento comercial ibérico.

É importante lembrar que o desenvolvimento de cada uma daquelas configurações socioespaciais ibero-americanas tende a apresentar implicações regionais diferentes para a rede urbana e sua articulação política com a Metrópole, dependendo da conformação do capital metropolitano dominante. Vale lembrar que essas redes se multiplicam e tendem a desigualdade porque sempre privilegiam polos urbanos onde a transação maximiza o controle e, sobretudo, os ganhos dos capitais internacionais, que de início estiveram sob a dominação colonial mercantilista e atualmente estão controlados pelas finanças do capital globalizado. Não é por acaso que Arrighi (1996, p. 317) alerta para que não se exagere na "analogia entre as empresas multinacionais do século Xx e as companhias de comércio e navegação dos séculos anteriores".
Trata-se, segundo Arrighi (1996), de dois tipos de organização empresarial, que fundamentam as situações de dependência por duas "lógicas maximizadora" de ganhos, uma do lucro da produção do capital e outra das rendas da expansão comercial, que convergem para a "via única" de acumulação ampliada do capital. Essa acumulação se concentra, como afirmado acima, nos espaços que apresentam "vantagens de posicionamento" e desenvolvem centralidades. Cria-se, nesse processo, as situações de domínio sobre os espaços em desvantagem e, historicamente, pode se verificar como isso aconteceu. Prado (1979), historiador brasileiro, distingue dois tipos de ocupação da América: as colônias de povoamento e as colônias de exploração. Nessas últimas predominou o trabalho compulsório pela escravização de africanos ou pela servilização dos naturais da terra, e estas colônias estavam em maior desvantagem e submetidas à lógica de expansão mais predatória da colonização: a busca de rendas da expansão comercial dos países ibéricos. Essas diferenças de lógicas e de posicionamento fizeram nascer a desigualdade e os processos que se aprofundaram e continuam crescendo entre as distintas configurações espaciais.

Nesse sentido, é significativo uma recente crítica da urbanização que afirma que "lo próprio de la urbanización contemporánea no’ es la conformación de una red mundial de 'ciudades globales' sino que 'la extensión desigual de este proceso de destrucción creativa capitalista a escala planetaria" (Sabatini \& Trebilcock, 2013, 
p. 50). Para essa formulação, o específico não seria a grande concentração espacial e do valor, mas a desigual distribuição da riqueza gerando distanciamento socioespacial no território e na cidade, como um problema urbano.

Com foco no Estado e na acumulação, para Arrighi (1996) o problema se coloca de outra maneira com outra prioridade: a questão do poder capitalista disperso ou de um poder concentrado. Enfim, discute como o Estado lida com o capital e problematiza como a sua organização política identifica-se ou não com a organização capitalista. Por isso, entendo que o resgate de sua discussão permitiu destacar os dois tipos de organização acima mencionados, e compreender como na via única da acumulação a lógica maximizadora do lucro e a lógica maximizadora da renda se bifurcam. E que todo o problema é que essa "bifurcação cria um campo de turbulência" (Arrighi, 1996, pp. 238-239) e disputas de forças políticas no enfrentamento de crises sistêmicas, pontos de ruptura, descontinuidade, enfim de instabilidades que organizações capitalistas e não capitalistas procuram equacionar conforme suas metas de maximização e escala de atuação. $\mathrm{O}$ interesse dessa rápida recuperação foi apontar para a necessidade de aprofundar o estudo dessas organizações e lógicas reescalonando a produção global e a produção imediata do espaço e do valor.

Nessa direção, observo que foi considerando a escala local e a produção imediata do espaço que se observou em diversas metrópoles, como do caso chileno de San- tiago, que se generalizam formas territoriais desiguais, tão polarizadas em termos de valor quanto as que foram caracterizadas enquanto formas urbanas surgidas da reestruturação pelos nomes extremos e polarizados de "precariópolis estatal e privatópolis inmobiliaria". Nessa caracterização, se assinalou para a necessidade de um esforço global e local de análise (vertical e horizontal), tanto que concluiu que as "ciudades no responden de modo homogêneo. Así los actores que actúan a la escala global pueden ser los mismos pero no en el ámbito local, pues este es expresión además de la relación produción-capital, de procesos históricos, culturales y sociales que transcienden esa problemática y que otorgan un marco fundamental para comprender las manifestaciones de la expansión metropolitana en los países latinoamericanos" (Hidalgo, Borsdorf \& Zunino, 2008, p. 190). Assim, sem descartar as implicações do reordenamento socioespacial das escalas para o desenvolvimento de cada uma daquelas conformações regionais, cabe retomar a importância na perspectiva da hipótese desse artigo notando que há inflexões na produção do espaço latino-americano em que as cidades alteram o seu significado, abrindo-se a possibilidade de não continuarem coloniais: "São Paulo é um espaço parcial do Brasil, originariamente irrelevante, posteriormente dominante" (Novy, 2002, p. 190). Ela, desde a fundação do assentamento colonial, significava politicamente a presença do poder metropolitano para o qual deveria garantir a ordem e a conquista territorial, o que significava controlar o uso territarias 34 
econômico de um território para o qual ela servia como correia de transmissão. Esse duplo significado político e econômico do assentamento colonial tinha implicações na organização de um espaço mais amplo do que as atividades que ocorriam nos limites de seu espaço. Assim, a cidade começou como representação da política, sobretudo, do poder econômico metropolitano para o qual deveria garantir internamente a ordem e o domínio do território. Apenas aos poucos, no espaço latino-americano, a cidade, tal como São Paulo, se tornou lugar de vida plural e formação social do povo. Embora, ainda, seja um espaço incipiente para o cidadão exercer seus direitos.

A cidade, no século XIX, passa por uma metamorfose urbana, quando começa a ser produzida como mercadoria. Por isso, moderna e fragmentada em propriedades começa a ser comercializada aos "pedaços" em lotes com preços maiores ou menores, conforme o comércio de aluguel. $\mathrm{O}$ avanço desses negócios foi substituindo o de escravos tornando-se comum alugar "casinhas" e cortiços. Essa substituição inclui a formação do mercado de compra e venda de terras e de edifícios estimulando a produção do espaço urbano como parte de um complexo de negócios imobiliários (Pereira, 2004). No transcorrer desse século começaram a mostrar importância os melhoramentos urbanos, levando à realização de obras de saneamento, arborização, abertura de ruas e praças. Em São Paulo, como em outras cidades, essa transformação significou uma metamorfose da riqueza que associada à proibição do tráfico de escravos sinaliza o fim da riqueza baseada na propriedade de escravos e o começo do que chamou de cativeiro da terra (Martins, 1979). Trata-se de transformação profunda e não de mera passagem para uma nova simbiose do trabalho e da técnica de construção com a terra no desenvolvimento da urbanização (Pereira, 1988). Por que não uma revolução imobiliária? Uma acomodação da lógica maximizadora da renda capitalizada da terra correndo no sentido de negar no espaço latino-americano o tempo imposto pela Revolução Industrial, tanto que essa capitalização da renda afirma a moderna propriedade da terra na generalização da forma mercadoria, mas é negação do lucro na produção da mais valia.

Ainda que em algumas cidades tal simbiose da produção capitalista, imediata e globalizada, do espaço urbano possa se apresentar menos desenvolvida, cabe ter em conta que a urbanização é um metabolismo social. Trata-se de uma transição a partir da qual emerge uma articulação entre o capital, o trabalho e a terra ("a mãe natureza") para a produção capitalista do espaço e do valor. E, é envolta em tal entrelaçamento que vemos progredir a produção capitalista com a presença de relações não capitalistas e a partir da reprodução dessa coexistência se pode compreender como persiste na América Latina, apesar da transição capitalista, a reprodução dessa simbiose, que embora funcional à reprodução capitalista manifesta irracionalidades tanto na urbanização quanto na industrialização.

\section{territarias 34}




\section{Transição capitalista e relações não capitalistas na cidade do capital}

A história de São Paulo apresenta particularidades em sua construção, mas como o desenvolvimento urbano de qualquer cidade revela um caminho que, como o de tantas outras cidades latino-americanas, permite identificar momentos em que há caracteres que tipificam a urbanização da América Latina.

Em São Paulo se ressalta que em seus primeiros séculos, a construção da cidade foi toda realizada com taipa de pilão. Inclusive os edifícios "monumentais" como a implantação da Casa de Câmara e Cadeia, foram construídos com essa técnica rudimentar mesmo que simbolicamente eram edifícios que serviam para materializar na Colônia a representação do poder português. A vila colonial se organizava com simplicidade, mas com forte dominação metropolitana visando efetivar as estratégias da conquista e de exploração territorial. Essas relações de domínio econômico e político se efetivavam com uma produção insipiente onde predominou o uso do trabalho compulsório, primeiro com colonos e jesuítas disputando os "negros da terra" e depois pela introdução de pessoas escravizadas e trazidas da África. Assim, a vila de São Paulo permaneceu por séculos com uma vida provinciana bastante acanhada, até se ver transformada pela modernização da riqueza, quando o monopólio da propriedade capitalista da terra substitui o da propriedade de escravos. Nessa lenta transição, emergia uma nova ordem social e urbana associada ao incremento do poder econômico da cafeicultura a partir dos meados do século XIX.

Cabe lembrar que, mesmo muito antes da Independência, já ocorria na Colônia um enfraquecimento político dos laços com a metrópole, que se fragilizavam interna e externamente com as crises do mercantilismo e mostravam sinais de uma lenta ruptura com o chamado Sistema Colonial. Todavia foi na primeira década do século XIX, com a vinda da Família Real e depois com a permanência no Brasil do herdeiro do trono português, que se consolida uma ruptura com a antiga ordem colonial. A fundação do Império Brasileiro significa uma importante política de superação da situação colonial porque nega o Poder Metropolitano, mas não o nega completamente, até porque o que era novo surgia como continuidade do velho: saiu o pai e permanecia o filho herdeiro. Todavia a riqueza e a sociedade se modernizaram, mas de maneira incompleta porque sem qualquer ruptura política que revolucionasse a relação entre a economia e o poder, como estava acontecendo com o aburguesamento da sociedade europeia (Martins, 1994, p. 30).

Em simultâneo a esses processos institucionais da organização política internacional pelo qual se formamos estados nacionais, há a constituição de relações capitalistas características das sociedades modernas. Trata-se de um processo social que transita para o predomínio econômico de relações capitalistas de produção, em que a vida, inclusive nas antigas colônias, passa a 
materializar, expressar e projetar no espaço produzido e no uso capitalista do território, os conflitos manifestos na emergência de uma economia de mercado.

Enquanto, na Europa, nos principais centros econômicos se construíam as "grandes cidades" como Londres e Paris, e aconteciam as revoluções técnicas e sociais de caráter capitalista, no espaço latinoamericano a negatividade desse movimento burguês e industrial, significativamente, estabelecia o fetiche da mercadoria capitalista, mas não as virtualidades revolucionárias dessa nova classe em emergência. Na América Latina, a imposição da equivalência das mercadorias pela acumulação mundial metamorfoseava a riqueza social brasileira. A propriedade da riqueza nova passava a ser representada pela renda territorial capitalizada, pelas fazendas e engenhos que se tornavam as mais importantes industrias de exportação, tendendo a romper com o que era, até então no Brasil, a maior representação de riqueza: a renda capitalizada da propriedade de escravos. Essa formulação sintética da transição para relações capitalistas permite compreender porque, no primeiro século da colonização portuguesa, a posse de terras nada valia e o decisivo era a posse de escravos (Pereira, 1988). E, também, porque a partir desse momento com a superação da antiga instituição das sesmarias, que era uma herança colonial, e a afirmação da moderna propriedade da terra, por meio da Lei de Terras de 1850, começa-se a impactar no acesso e custos da construção imobiliária. A partir dessa legislação moderna ocorre a mudança do regime de propriedade levando e a afirmação da renda capitalista da terra, mesmo para a propriedade dos edifícios modestamente alugados a presença dessa renda capitalizada passa a ser uma premissa da economia urbana em transição. Desde então, pode-se considerar que o preço da terra manifestase, conforme Marx, determinado pela capitalização das rendas futuras.

A novidade dessas manifestações da transição capitalista favorecia a urbanização, ainda na cafeicultura e inicios da industrialização fabril. O aumento do número e do porte das cidades paulistas, o fortalecimento da presença do trabalho assalariado em contraste com o trabalho aplicado no campo e, também, a incipiente constituição de infraestrutura em redes, desde o saneamento até os vapores transatlânticos, passando pelas ferrovias, que adentram e reorganizam o território aumentando a possibilidade de inclusão da renda da terra no sistema econômico nacional. Talvez por essa presença forte da forma renda, no Brasil, a superação da escravidão foi morosa e a implantação do trabalho livre manteve-se lenta, e só foi impulsionada quando a economia primária exportadora capitalista com base na forma lucro do cálculo do fazendeiro da cafeicultura do chamado Oeste Paulista começou a se expandir e a utilizar predominantemente o trabalho imigrante, se opondo à tradicional cafeicultura do complexo escravista do Vale do Paraíba.

É conhecido que esse desenvolvimento da produção capitalista com trabalho livre em substituição dos escravos na cafeicultura 
provocava um enriquecimento febril sob a forma de renda territorial capitalizada, que no conjunto da economia cafeeira era gerada pelas enormes plantações de café que funcionavam como uma verdadeira "indústria de fazendas" (Martins, 1979). A generalização da propriedade territorial como mercadoria transformava, simultaneamente, o significado econômico da propriedade da terra para o uso agrícola e dos terrenos para a construção em São Paulo. $\mathrm{E}$, por isso, impactou a construção da cidade eliminando os edifícios de taipa e a sua aparência colonial, num processo que foi denominado por Lemos (1985) de implantação da "alvenaria burguesa". Abrangendo um período mais longo Fernandes (1965) fala em constituição do burgo durante o século XIX: "São Paulo aparecia como o primeiro centro urbano especificamente burguês". O ano de 1872, início da administração de Theodoro, ficou conhecido como de uma Segunda Fundação da Cidade de São Paulo não só pela nova relação da arquitetura com a urbanização associada ao uso da alvenaria de tijolo, mas principalmente porque tinha a ver com mudanças significativas no trabalho, na propriedade da terra e na função econômica da cidade (Pereira, 1998 e 2004).

Foi em meio a essa movimentação aparentemente desconexa, na passagem dos meados do século XIX para o XX, que a economia paulista aprendeu a acumular o capital industrial, mesclando a economia da grande agricultura de exportação com a da industrialização urbana. O domínio dessa forma de acumulação tem origem no café, inclusive porque logo os fazendeiros diversificam os seus investimos em inúmeras atividades industriais, fazendo avançar a reprodução capitalista nos poros da economia cafeeira (Martins, 1979). O forte da industrialização corre em direção à substituição de importações, criando fábricas, obras urbanas e demandando infraestrutura. Ampliava-se o quadro da reprodução social capitalista já com alguma aglomeração fabril, que reunia estabelecimentos com produção significativa e unidades especializadas em alguns bairros paulistanos. A diversificação dos investimentos estimulava a homogeneização da produção industrial nos diferentes setores da economia e transformava a cidade de São Paulo de pequena capital da Província em um centro comercial, financeiro e base da concentração industrial regional (Pereira, 1988).

Outro aspecto dessa transição que também ganha relevância social é o notável branqueamento da população posto em destaque por Fernandes (1965), que começa lento, mas se consolida com a chegada de grandes levas de europeus. Desde meados do XIX, a presença de imigrantes no Porto de Santos preparava a Abolição e, com os que permaneciam na Capital paulista procurando escapar do trabalho nas fazendas de café, se montava na cidade tanto um mercado de trabalho como de aluguel de casinhas, significando alguma mudança no mercado de terras, de casas e na encomenda para construir, muitas vezes, para alugar. Nesse contexto, parte desses imigrantes, em sua maioria italianos acabou dominando o mercado incipiente, perma- territorios 34 
necendo nas atividades de construção e participando da realização de obras de qualificação urbana no centro e bairros de São Paulo. A urbanização floresceu tanto que a cidade recebeu nomes tais como Cidade dos italianos ou São Paulo dos Fazendeiros, que expressavam a percepção das diferenças sociais. Todavia ficou conhecida a expressão: "São Paulo quem te viu e quem te vê", que marcava a ruptura radical que ocorria na cidade, na construção e na arquitetura de seus edifícios públicos e privados (Pereira, 2004).

Essa expressão difundida em 1900 era uma imagem eficaz da impressão que causava o dinamismo das obras urbanas e da construção imobiliária como projeto da elite cafeeira, que se urbanizava e buscava a industrialização fabril. Essa expansão física e econômica da cidade associava-se a um aumento significativo da participação de europeus, particularmente de italianos, no conjunto da população que passou de pouco mais de 30 mil, em 1872, para cerca de 200 mil habitantes na virada do século. Essa movimentação demográfica "europeizava” a fisionomia da cidade, que revigorada pelo desenvolvimento dos negócios comerciais, bancários e industriais gestados no ordenamento capitalista da economia cafeeira, atingiu, em 1930, o primeiro milhão de habitantes.

No bojo desses processos de concentração industrial, a atividade do complexo da construção não se diferenciou das demais atividades da indústria e acompanhou a reorganização da produção de materiais e equipamentos da construção civil com caráter fabril. Assim, na virada e primeiras décadas do século Xx, acabaram sendo criadas fábricas e oficinas embrionárias de um forte segmento de materiais de construção, que gerava internamente produtos de madeira cerâmicos, metálicos, e outros. A introdução de conhecimentos da tecnologia moderna de construção se mostrou tão expressiva como na indústria em geral, mas o progresso nas construções beneficiou principalmente uma parte da cidade, que ficou mais bem servida por obras e serviços urbanos e tendeu a concentrar a construção de edifícios mais altos, que vieram se associar ao uso intensivo de alguns materiais de construção, especialmente do cimento. A altura desses edifícios, principalmente na área central das cidades, contornava e implicava na alta dos preços dos terrenos, que já estavam em espaços adequadamente urbanizados. Por isso, vale lembrar que os primeiros edifícios em altura foram significativamente chamados de "gaiolas de ouro", porque apenas poucos podiam pagar, e as casas superlotadas e encortiçadas de “caxotins humanos", onde famílias se cotizavam para alcançar o preço do aluguel.

As famílias abastadas podiam continuar encomendando palacetes, mas criava-se um novo contexto, em que famílias remediadas e menos abonadas puderam se beneficiar da produção moderna de materiais de construção à medida que estas mudanças industriais barateavam a construção ou até criavam facilidades técnicas para a construção da casa. De certa maneira pode se considerar que estas famílias estavam em situação melhor do que quando a única 
opção do morador, por absoluta falta de recursos, era apenas improvisar uma construção e ocupar de maneira absolutamente improvisada algum lote "disponível". $\mathrm{Na}$ diversidade das soluções de moradia criadas pela urbanização e pela industrialização a questão do acesso à casa manteve-se como centro dos conflitos e item das demandas nas lutas urbanas. Assim, já no início do século e principalmente após os anos 1930, a casa a ser adquirida pela compra se tornou menos acessível, tendo sido a moradia um problema desde o princípio solucionado com alternativas não capitalistas de acesso ao lote. E, por isso, em meio ao crescimento da cidade e da indústria se recriava uma mescla de relações não capitalistas com relações capitalistas desenvolvidas. Essa mescla assegurava a continuidade da reprodução do capital, agora industrial e urbano, apresentando uma nova realidade, agora mais intrincada e complexa. Assim, não há nenhum dualismo ou dicotomia na formulação dessa mescla, mas a sugestão de um refinado entendimento das intrincadas relações da reprodução social do capital.

Não se trata, portanto, de pensar como a modernização da construção da cidade capitalista supera a segmentação dessas relações, mas de lembrar que é o próprio capital e seu desenvolvimento que cria a heterogeneidade e recria a combinação dessas relações. Sendo importante ressaltar que do ponto de vista setorial da Construção, essa dificuldade na homogeneização do desenvolvimento técnico e econômico caracteriza a compreensão das particularidades da indústria da construção. Este setor, embora industrial, não apresenta um desenvolvimento semelhante ao da indústria fabril, apresentando uma industrialização que ainda precisa ser historicamente melhor observada sob o ponto de vista das formas sociais de produção do espaço, e não pode ser reduzida ao ponto de vista apenas da técnica da construção. Não é excessivo enfatizar a importância do estudo das formas de produção do espaço proposta por Jaramillo (1982) definidas a partir da articulação dos agentes no processo de produção e circulação do espaço urbano construído. Note-se que as formas de produção (autoconstrução, por encomenda, mercado e estatal), conforme o citado autor, apresentam articulações dos interesses dos agentes que as definem e permite compreender a razão do chamado "atraso da construção".

O uso reticente da maquinaria e da técnica na indústria da construção difere do que ocorre na fabricação de produtos industriais e permitiu o entendimento de que o setor da construção seria um ramo industrial atrasado. Trata-se de uma visão que coloca os sistemas construtivos em contraposição aos sistemas de fábrica considerados mais avançados e tecnicamente modernos, sem considerar as particularidades da construção. Tanto que das frequentes comparações com a fabricação têxtil, que é atividade industrial que usa maquinário de modo expressivo, concluíram que a construção é "atrasada”. Entretanto, essa conclusão, por se reduzir à visão fabril, se mostra equivocada no exame da indústria da construção porque obscurece as suas particularidades chegando a ignorar a territarias 34 
diversidade das formas de produção, o que no mínimo oculta o imbricamento dessa indústria com a propriedade da terra e com a urbanização. Foi na observação histórica desse duplo processo de industrialização e de urbanização que se considerou, como emergem as formas de produção doméstica, produção por encomenda, produção para mercado e produção estatal na construção da cidade de São Paulo (Pereira, 1988 e 2004).

$\mathrm{Na}$ polêmica sobre a industrialização da construção, aparentemente, a interpretação do atraso poderia ser justificada pela existência, nas cidades latino-americanas, de uma massa de trabalhadores com disposição a se empregar por salários reduzidos. Assim, considerando que o uso intenso do trabalho industrial é sinal de insuficiência técnica, a causa do "atraso" industrial da construção seria a abundância de mão de obra barata (Singer, 1978). De um lado, a possibilidade de utilizar trabalhador mal pago na produção explicaria o pouco uso de maquinários e de técnicas modernas na construção, e o desinteresse do empresário em investir capital fixo nos canteiros de obras. De outro, o assalariado mal pago (independente do setor) não encontra moradia com aluguel que possa pagar senão em local precário e inadequado. De maneira que a ideia de atraso na construção parece encontrar justificativa, também, na visível quantidade de casas construídas pelo próprio trabalhador em fuga do aluguel. Mas, tal visibilidade não evidencia a articulação entre o urbano e o industrial que precisaria ser estabelecida pela análise dos elementos interpretados. Tanto que induz a um convencimento precoce onde o visível obscurece o que precisaria ser compreendido considerando a especificidade do desenvolvimento técnico da indústria da construção e da articulação das suas diferentes formas de produção.

Importante é reter que Jaramillo (1982) estudou a coexistência das formas de produção que distinguem o desenvolvimento da construção do modelo do industrial fabril, mas justamente para demonstrar que entre as razões do atraso da construção estava a propriedade da terra como um obstáculo ao desenvolvimento industrial. Por essa interpretação, sua análise dá um passo à frente e outro para traz, porque destaca as formas de produção, mas não nega a visão industrial; antes a reafirma porque foca a questão da terra apenas como um obstáculo à reprodução industrial do capital e não observa que com a propriedade da terra se cria uma particularidade na valorização do capital na construção. Assim, ainda é preciso esclarecer que "o processo de trabalho na construção se particulariza no processo de valorização, por ser potenciado pela valorização imobiliária e não concorrer para redução do tempo de trabalho social" (Pereira, 1984, p. 15).

De maneira que por essa interpretação prevalece o obscurecimento que não compreende as particularidades da industrialização da construção em seus vínculos com a urbanização e nem se aprofunda em como ocorre a instrumentalização do uso da terra no setor pelas diferentes formas de produção. Assim, a visão industrial obs- 
curece o entendimento das ambiguidades do desenvolvimento moderno das cidades latino-americanas, porque ora é o excesso de mão-de-obra barata que se apresenta como impasse ao desenvolvimento industrial da construção, e ora é a propriedade da terra que se apresenta como um obstáculo a industrialização. Tal entendimento cega a relação entre o capital, a terra e o trabalho, homogeneizando as relações de propriedade de coisas distintas e naturalizando a explicação do atraso na construção, como se fosse um fenômeno industrial-fabril. Torna crível que seria o rentismo - um ganho ocioso proporcionado pela simples retenção da terra - a explicação de toda inoperância do empresariado industrial e da gestão urbana. Assim, a retenção da terra ociosa seria o fundamento de todas as mazelas da cidade e não um resultado de como a construção da cidade é instrumentalizada para a reprodução do capital. Aliás, é essa interpretação redutora, naturalizada e conservadora do desenvolvimento urbano transposta à industrialização que faz com que a visão industrial atribua à habitação a pecha de problema insolúvel. Hoje, sabemos que mesmo as experiências de políticas habitacionais de mercado subsidiado com a presença de grandes construtoras amplamente apoiadas pelo Estado, como aconteceu recentemente no México e no Brasil, não aumentaram a capacidade em solucionar pelo mercado o problema social da habitação.

Por isso, é importante frisar que na crítica a essas interpretações conservadoras há necessidade de superar a visão industrial para compreender a construção da cidade como um processo não fabril e na perspectiva da dimensão urbana. A visão industrial não compreende o que é urbanização e impede o conhecimento das particularidades que assume a construção em cidades latinoamericanas, onde por razões históricas se tornou persistente a forma de produção doméstica: o morador construindo sua casa própria. E por ser a forma predominante na estrutura urbana dessas cidades tipificou a presença de relações não capitalistas na produção do espaço capitalista: uma urbanização dependente. Nenhuma novidade, trata-se de uma produção não mercantil da casa que é construída pelo próprio morador, que se tornou conhecida com o nome de autoconstrução. Mas, como essa interpretação reduz a forma de produção ao de um autoconsumo, não a entendeu como esta forma de produção capitalista da cidade não apresenta relações capitalistas de produção apesar de produzir o espaço mais habitado das cidades latino-americanas. E, assim, por não entende-la articulada na estrutura urbana com as outras formas de produção capitalista, tem dificultado que a análise do processo global da produção do espaço avance no exame das diferentes situações urbanas como uma totalidade: segmenta o estudo das formas de produção capitalista da construção e obscurece como a forma mais "moderna" se articula com a mais "atrasada" na construção da cidade.

Na América Latina, essa combinação de relações não capitalistas com relações capitalistas ocorre tanto nas relações de produção, como nas relações de apropriação e 
acesso à moradia. Não seria essa articulação de diferentes relações uma importante peculiaridade da produção do espaço nas cidades latino-americanas? Aliás, tal como foi essa peculiar combinação de relações que particularizou a ocupação territorial e a colonização ibero-americana, não seria esta mescla um elemento essencial para conhecer a simultaneidade e entrelaçamentos das várias formas de produção do espaço nas cidades? E, é devido a essa incompletude da modernização que, na maioria das vezes, mesmo o assalariado de grandes empresas industriais, ainda atualmente, só obtém o acesso a casa por meio de uma produção não mercantil ou, mais recentemente, por meio de políticas habitacionais apoiadas com fortes subsídios públicos. A unidade desses processos que envolvem relações sociais distintas - combinando relações capitalistas e não capitalistas - como uma totalidade implicam em desafios para o avanço da compreensão histórica e da discussão teórica da realização contemporânea da formula trinitária do valor na periferia do capitalismo, e de como a terra, o trabalho e o capital na América Latina se inseriram, historicamente, na economia mundo.

Para isso, primeiro cabe relevar que essa situação de aparente "atraso" da construção da cidade não é mera permanência de algo superado, nem que representaria mera persistência ou apenas sobrevivência de algo do passado. Trata-se de um processo histórico particular que se repõe como questão atual, e para a qual não é menos importante considerar que apresenta um aspecto setorial, ou seja, se constitui em particularidade de como se realiza e avança a produção capitalista em determinado setor. Além disso, as formas de produção do espaço tendem a se multiplicar, conviver e têm encontrado maneiras de entrelaçar a diversidade de suas formas com a exigência econômica do capital quanto ao desenvolvimento técnico, social e urbano. Mas, essa maneira com que se realiza a construção da cidade não tem respondido às necessidades de preservar a natureza e nem à dignidade do habitar humano. Por isso, o que está em questão é a totalidade do desenvolvimento da produção do espaço urbano latino-americano. Não se trata apenas da precariedade de uma casa ou de um bairro, mas sim da desigualdade urbana na dimensão da cidade em uma formação espacial específica que precisa ser pensada como um espaço supranacional - um conjunto de paísesque, historicamente, foram colocados na periferia do desenvolvimento da economia mundial pela persistência dos métodos da acumulação primitiva de capital.

Assim, num nível, a história da produção do espaço da cidade latino-americana se insere na acumulação primitiva tal como essa acumulação, atualmente, se insere na construção da precariedade urbana como produção não mercantil, numa sociedade cada vez mais produtora de mercadorias. Daí será possível concluir dizendo que na produção do espaço das cidades latinoamericanas, apenas mudaram-se os rótulos de maneira a manter persistente as antigas desigualdades. Será, então, que apesar da precariedade da urbanização contemporânea, pobres e moradores em condição de 
rua só agravam as mesmas interdições próprias da condição de existência colonizada e apenas atualizam os fundamentos do antigo conceito de colonizado.

Assim, num nível, a história da produção do espaço da cidade latino-americana se insere na acumulação primitiva tal como está acumulação, na atualidade, se insere na construção da precariedade urbana como produção não mercantil, numa sociedade cada vez mais produtora de mercadorias. De maneira que a constituição das formas urbanas ocorrem combinadas, reescalonadas e involucradas merecendo aprofundamento em pesquisas para que o conhecimento sobre as relações capitalistas em simbiose com relações não capitalistas na produção do espaço seja reinterpretado e os fundamentos da questão melhor compreendidos. Será possível, então, finalizar reiterando que na produção do espaço das cidades latino-americanas, apenas mudaram-se os rótulos para manter persistente as antigas desigualdades. Mas, é incerto que na precariedade da urbanização contemporânea, pobres e moradores em condição de rua apenas agravam as mesmas interdições próprias da condição de existência colonizada e só atualizam os fundamentos do antigo conceito de colonizado.

\section{Considerações finais: globalização financeira e a reestruturação imobiliária}

Desde os anos 1970, com diferentes ritmos e intensidades, ocorreram diversas reestruturações associadas a economia globaliza- da. Nos anos 2000, sob hegemonia das finanças globalizadas, esses movimentos do capital despertaram ainda maior atenção porque desencadearam crises de alcance mundial e intensificaram reações políticas com diferentes calibres visando reformas neoliberais com ajustes no trabalho, no imobiliário e no financeiro.

De maneira que nas últimas décadas “la 'ideología neoliberal' se há asentado ahora en la mayor parte del mundo, quizás con la excepción de algunos países latinoamericanos del arco bolivariano, como un fundamento naturalizado" (Hidalgo \& Janoschka, 2014, p. 8). Essa ideologia apresenta orientação muito precisa buscando escancarar os limites da política urbana para o capital e aprofundar os processos espoliativos financeiros e imobiliários. Esses processos já não se limitam à tradicional espoliação urbana e de trabalhadores de famílias vulneráveis que não conseguem pagar por uma habitação digna recebendo pouco por seu trabalho conforme análise de Kowarick (1979 e 2000) da luta social na produção do espaço. Por isso, é relevante compreender como na urbanização latinoamericana estão presentes diferentes processos espoliativos resultantes de coalizões de forças específicas, que ainda precisam ser melhor conhecidas, até porque as novas políticas estão implicando em um urbanismo empresarial privatista, que apresenta equações peculiares a cada país e cidade.

Assim, tal como o equacionamento dessas políticas em São Paulo pode se distinguir daquele do Rio de Janeiro, cabe notar que ambos tendem a se diferenciar 
daqueles que se realizam em Bogotá, Lima, Santiago do Chile assim como de outras cidades. Apesar dessas diferenças, o relevante a considerar é que tais equações se fundam em movimentos contraditórios que combinam processos de exploração do trabalho com o que foi denominado por Harvey (2004) de acumulação por espoliação. De maneira que esses movimentos se manifestam mundialmente ora como instrumentalização, tradicional, da terra pelo capital, ora como instrumentalização de espaços, metamorfoseados, na reprodução do capital na cidade contemporânea.

Embora de dimensão planetária esses conflitos urbanos são localizados e apresentam homogeneidade regional que resulta da movimentação capitalista mundial sendo significativo notar que as tendências recentes de crise associadas à reestruturação de políticas imobiliárias e financeiras, inclusive habitacionais como a crise dos subprime (Harvey, 2011). O artifício continua sendo a instrumentalização da privatização da terra, do espaço e o resultado a reconfiguração da cidade como elemento estratégico de sobrevida e recuperação da rentabilidade do capital (Lefebvre, 1970, 1972, 1973). Devido a esse fundamento na propriedade imobiliária foram paulatinamente destruídos os obstáculos sociais e legais para a valorização imobiliária e se priorizou superar as situações de crise por meio da realização de megaprojetos (Pereira, 2011). O que fortaleceu os laços rentistas do financeiro com a atividade da construção porque a rentabilidade dos negócios imobiliários não poderia significar, por muito tempo, imobilidade de capital na propriedade tornando o investimento (i)líquido (Hidalgo \& Janoschka, 2014).

Nessa mesma direção, esses autores frisam que os investimentos imobiliáriofinanceiros manipulam a produção do espaço fazendo com que se consolide um padrão mais desigual de segregação urbana como verdadeira fragmentação social. De forma que estes processos imobiliários, por viabilizarem a reprodução do capital em condições sociais tão perversas manifestam e impulsionam a atual dissolução urbana. Assim, como tentativa de síntese se poderia dizer que o capitalismo histórico, que tinha sido forjado na sua origem com a utilização de métodos não capitalistas, atualmente não dispensa o convívio com essas relações de apropriação e captura típicas da acumulação primitiva para manter sua reprodução social com maior intensidade e desigualdade. Por isso, a mescla predatória dessas relações persistem no espaço latinoamericano apesar da reprodução expansiva do capital mundial manifestar-se com uma hierarquia especificamente capitalista que se apoia na homogeneização das relações sociais (Lefebvre, 1980). Verifica-se, portanto, a permanência de uma produção capitalista de relações não capitalistas que faz conviver a reconfiguração da cidade contemporânea com a reestruturação da construção imobiliária (e de infraestruturas) como produção de espaços metropolitanos extremamente desiguais. Não é por acaso, que a publicação da ONU (2014) ressalta que embora se possa dizer que o ritmo do crescimento da desigualdade 
esteja diminuindo, atualmente, a América Latina se constitui na região mais desigual do mundo.

A reestruturação imobiliária exacerba e manipula essas desigualdades, que revelam-se como fragmentos urbanos e sociais. Instrumentalizada por coalizões (im)postas pelas movimentações recentes do capital, aprofunda as segmentações que produzem o espaço segregado e privatista destruindo a cidade existente. É conhecido que a privatização imobiliária ressignifica a cidade, o planejamento e as intervenções urbanas como mero negócio espoliativo. Esse é o sentido da reestruturação em que a discussão dos atuais processos imobiliários vem apoiando-se em novos instrumentos das políticas públicas, como as operações urbanas e parcerias que priorizam o megaprojeto, porque este movimenta maior volume de investimento e maximiza a capitalização da renda da terra e do capital globalizado.

No bojo desse movimento destaque-se os chamados condomínios, que independente do uso, emergem como uma forma de apropriação do espaço que potencializa a mercantilização da vida e a sua privatização. Porque a forma condomínio exacerba a instrumentalização da cidade não só por intensificar a homogeneização urbana de maneira predatória, mas por maximizar as diferenças na captura de rendas. Tal homogeneidade, apesar de monótona, forja a sedução imobiliária elevando preços pela manipulação de pessoas em negócios onde o preço de monopólio faz o patrimônio imobiliário e financeiro gerar rendas cada vez maiores. Essa reestruturação tem uma dimensão global em que a internacionalização do movimento pela globalização financeira se consorcia com a produção imediata do espaço exatamente para produzir os mais altos preços monopolistas, aqueles de maior rentabilidade ao pôr em relevo os novos artefatos arquitetônicos em espaços urbanos inovadores. A elevação desses preços "aparentemente sem fim" consolida um espaço metropolitano, numa aglomeração cada vez maior e mais desigual, instrumentalizando a distribuição segregada dos grupos sociais no espaço. Nesse espaço metropolitano, o urbanismo empresarial, liberal e privatista emula a fragmentação, a expansão e (im)põem como "caos urbano" o que na verdade é uma organização hierárquica das coalizações da ordem próxima com a ordem mais distante uma hierarquização do espaço. Não mais urbano, porque esse espaço é produzido em função das necessidades da reprodução do capital e em prejuízo da força de trabalho.

Espaços confinados, megaprojetos isolados, mas planetariamente conectados por intensos fluxos mundiais que revelam a força e a fraqueza que unifica o setor imobiliário e o poder das finanças globalizada, conforme Chesnais (2005), no rentismo do patrimônio imobiliário e do patrimônio do mobiliário. A titulação das hipotecas incentiva o endividamento e a criação de negócios derivados do consórcio entre o financeiro e o crédito imobiliário de maneira inimaginável (Daher, 2013). Um negócio patrimonial em que a propriedade mobiliária, tal como a imobiliária, torna-se 
fonte de rendas e ambas as propriedades funcionam como "capital patrimonial", que viabilizam a captura de excedente criado em outra esfera (Chesnais, 2005). Nesse sentido, a externalidade desses movimentos atualiza e revela o fundamento para compreender a mistificação da forma valor e da capitalização das rendas. Isso porque a valorização do capital envolve tanto o processo global de produção do valor e do espaço quanto o processo imediato desta produção, portanto, de mera construção da cidade torna-se a um processo total de produção em que as relações sociais são transformadas em propriedades das coisas, um "fetichismo da mercadoria", conforme Marx, pelo qual os rendimentos aparecem como resultado das "coisas". Enfim, espaço e capital mobilizados pela privatização do valor (i)mobilizam-se em diferentes níveis da (re)produção social e fundamentam, mundialmente, o fetichismo do patrimônio (i)mobiliário.

Historicamente, a acumulação primitiva manifestou-se como origem e constituição das relações capitalistas, porém cabe considerar que essas relações persistiram não como "atraso", porque funcionais ao capital desde a colonização. A combinação dessas relações "primitivas" (supostamente decadentes) e "modernas" se mostram relações fundamentais, desde o século XIX, uma vez que se verifica que, na transformação da cidade de taipa para a alvenaria de tijolos, houve a emergência de relações especificamente "burguesas" tanto do trabalho quanto da propriedade da terra na condução do domínio do capital sobre a cidade (Fernandes, 1965; Pereira, 2004). Da mesma maneira, no transcorrer do século $\mathrm{Xx}$, com a expansão industrial e consolidação da cidade de São Paulo, manteve-se a coexistência combinada das formas de exploração do trabalho e das formas de espoliação, o que diversificou as soluções habitacionais e as formas de produção. Essa pluralidade de formas de produção do espaço revelada tanto pela riqueza urbana como pela precariedade implica numa multiplicidade de situações que indicam como a urbanização desigual favorece a industrialização: eleva ao máximo os preços imobiliários aumentando o excedente para a reprodução do capital e, simultaneamente, a precariedade reduz ao mínimo os custos da reprodução da força de trabalho.

Aparentemente contraditório, mas formulação típica aos processos da América Latina porque no setor fabril desenvolveuse uma visão industrial moderna e no da construção uma visão patrimonial rentista, que se mostraram funcionais à acumulação, até os anos 1970. Até então, para resolver problemas da industrialização foi significativo a redução do custo da força de trabalho e a (in)solução do problema habitacional proporcionado pela urbanização precária. Porém, nas últimas décadas, a construção imobiliária (e de infraestruturas) sob a hegemonia da acumulação financeira exacerbou os ganhos rentistas proporcionados pelo patrimônio imobiliário e mobiliário. Há ganhos patrimoniais tanto com a expansão territorial como na requalificação de espaços modernos degradados. A dimen- 
são do investimento imobiliário-financeiro sinaliza uma instrumentalização do espaço que reconfigura os problemas da cidade, antes de soluciona-los.

Enfim, se reitera a necessidade de atualizar a noção de acumulação primitiva ou originária para compreender a coexistência dos processos espoliativos, sobretudo, financeiros e imobiliários com a exploração "moderna" do trabalho. Essa compreensão leva à considerar que a combinação desses processos na passagem para o século XXI, significa que a globalização financeira e a reestruturação imobiliária tornam a cidade ainda mais injusta, segregada e excludente.

\section{Referências}

Amaral, A. (1981). A hispanidade em São Paulo. São Paulo: Nobel/Edusp.

Arrighi, G. (1996). O longo século XX. Dinheiro e poder e as origens de nosso tempo. São Paulo: Unesp.

Castells, M. (1973). Imperialismo y urbanización en América Latina. Barcelona: Gustavo Gili.

Chesnais, F. (2005). A finança mundializada: raizes sociais e politicas, configuração, consequências. São Paulo: Boitempo.

Daher, A. (septiembre 2013). Sector inmobiliario y las crisis económicas. Revista EURE. Santiago de Chile: PUC, 39(118), 47-75.

De Mattos, C. (2010). Globalización, negocios inmobiliarios y mercantilización del desarrollo urbano. En De Mattos, C., Globalización y metamorfosis urbana en
America Latina (pp. 203-227). Quito: OLACCHI.

Fernandes, F. (1965). A integração do negro na sociedade de classes. São Paulo: Dominus/USP.

Furtado, C. (1964). Formação econômica do Brasil. Río de Janeiro: Fundo de Cultura.

Harvey, D. (1990). Los limites del capitalismo y la teoría marxista. México: FCE.

Harvey, D. (2004). Onovo imperialismo. São Paulo: Loyola.

Harvey, D. (2011). O enigma do capital e as crises do capitalismo. São Paulo: Boitempo.

Harvey, D. (2011). O enigma do capital e as crises do capitalismo. São Paulo: Boitempo.

Harvey, D. (2014). Cidades Rebeldes. Do direito da cidade à revolução urbana. São Paulo: Martins.

Hidalgo, R., Borsdorf, A., \& Zunino, H. (2008). Las dos caras de la periferia metropolitan de Santiago de Chile. En Pereira, P., \& Hidalgo, R. (Eds.), Producción Inmobiliaria y reestructuración metropolitana en America Latina (pp. 167-195). Santiago de Chile: IG-PUC.

Hidalgo, R., \& Janoschka, M. (2014). La ciudad neoliberal. Gentrificación y exclusión en Santiago de Chile, Buenos Aires, Ciudad de México y Madrid. Santiago de Chile: PUC-Chile, Serie Geolibros n. 19.

Jaramillo, S. (1982). Las formas de producción del espacio construido en Bogotá. En. Pradilla, E. (Comp.), Ensayos sobre 
o problema de la vivienda en México (pp. 149-212). México: UAM-Xochimilco.

Kowarick, L. (1979). A Espoliação Urbana. Rio de Janeiro: Paz e Terra.

Kowarick, L. (2000). Escritos urbanos. São Paulo: Editora 34.

Lefebvre, H. (1970). La Révolution Urbaine. Paris: Galllimard.

Lefebvre, H. (1972). Le droit à La ville suivi de Espace et politique. París: Anthropos.

Lefebvre, H. (1973). La survie du capitalisme. París: Anthropos.

Lefebvre, H. (1980). Une pensée devenue monde. Faut-il abandoner Marx? Paris: Fayard.

Lemos, C. (1985). Alvenaria Burguesa. São Paulo: Nobel.

Martins, J. (1979). O Cativeiro da Terra. São Paulo: Hucitec.

Martins, J. (1994). O poder do atraso. São Paulo: Hucitec.

Marx, K. (1983). O Capital. São Paulo: Abril Cultural.

Novy, A. (2002). A des-ordem da periferia: 500 anos de espaço e poder no Brasil. Petrópolis: Vozes.

ONU Habitat. (2014). Construcción de ciudades más equitativas. Politicas públicas para inclusión en América Latina. Nairobi: Programa de la Naciones Unidas para los Asentamientos Humanos, ONU Habitat.
Pereira, P. (junho 1985). Teoria e História: processos e problemas na urbanização dependente. Sinopses 7, (pp. 203-232). São Paulo: FAUUSP.

Pereira, P. (1988). Espaço, Técnica e Construção. São Paulo: Nobel.

Pereira, P. (1998). A modernização de São Paulo no final do XIX: da demolição da cidade de taipa à sua reconstrução com tijolos. En Sampaio, M. R. A. de, Habitação e Cidade (pp. 53-65). São Paulo: FAUUSP.

Pereira, P. (2004). São Paulo: a construção da cidade. 1872-1914. São Carlos: RiMa.

Pereira, P. (2011). Negócios imobiliários e transformações sócio-territoriais em cidades da América Latina. São Paulo: FAUUSP.

Pradilla, E. (2013). La ciudad capitalista en el patrón neoliberal de acumulación en America Latina. Seminário Internacional A cidade Neoliberal na América Latina. Río de Janeiro: Novembro.

Prado, C. (1979). Formação do Brasil contemporâneo. São Paulo: Brasiliense.

Sabatini, F., \& Trebilcock, M. (2014). Desigualdades, clasismo y mercados de suelo. En mesas hurtadianas exclusión social en Chile. Santiago do Chile: Universidad Alberto Hurtado.

Singer, P. (1978). Economia política da urbanização. São Paulo: Brasiliense. 